\title{
RELAÇÃO DA ASSIMETRIA DA INFORMAÇÃO, DA PARTICIPAÇÃO ORÇAMENTÁRIA E DO RISCO NA CRIAÇÃO DA FOLGA ORÇAMENTÁRIA
}

\section{RELATIONSHIP OF THE INFORMATION ASYMMETRY, BUDGET PARTICIPATION AND RISK IN CREATING BUDGET SLACK}

\author{
Carlos Eduardo Facin Lavarda \\ Doutor em Contabilidade pela Universitat \\ de Valencia, Espanha; Professor do Programa \\ de Pós-graduação em Ciências Contábeis da \\ Universidade Regional de Blumenau - FURB \\ clavarda@furb.br
}

Odir Luiz Fank

Mestre em Ciências Contábeis pela Universidade Regional de Blumenau - FURB Professor da FAI - Faculdades de Itapiranga/SC odirfank@hotmail.com
Contextus

ISSNe 2178-9258

Organização: Comitê Científico Interinstitucional Editor Científico: Marcelle Colares Oliveira Avaliação : Double Blind Review pelo SEER/OJS

Revisão: Gramatical, normativa e de formatação Recebido em 23/02/2013 Aceito em 30/01/2014

$2^{\mathrm{a}}$.versao aceita em $14 / 03 / 2014$

\section{RESUMO}

O objetivo da pesquisa é verificar a relação da assimetria da informação, da participação orçamentária e da posição de risco na criação da folga orçamentária pela média gerência de organizações. A pesquisa caracteriza-se como descritiva, com abordagem quantitativa, realizada por meio de levantamento, utilizando como instrumento de pesquisa o questionário. A amostra da pesquisa é composta por 171 alunos de cursos de pós-graduação lato sensu nas áreas de Contabilidade e Administração no estado de Santa Catarina que se enquadraram nos cargos gerenciais em suas organizações. Os constructos foram testados quanto à validade de escala por meio do teste de Alpha de Cronbach. Os resultados da correlação de Spearman mostram que não foi observada relação da participação, da assimetria da informação e do risco com a criação da folga orçamentária. Por outro lado, a correlação entre a assimetria e a participação orçamentária foi significante e positiva.

Palavras-chave: Folga orçamentária. Assimetria da informação. Participação orçamentária. Risco na decisão orçamentária.

\begin{abstract}
The aim of the research is to verify the relationship of asymmetric information, budget participation and risk position in creating budget slack by middle managers of organizations. The research is characterized as descriptive and quantitative, conducted through survey, using the questionnaire as a research tool. The survey sample consists of 171 accounting and management graduate students in Santa Catarina state that met the management positions. Constructs were tested through cronbach's alpha reliability scale. Regarding participation, information asymmetry, risk and budgetary participation there are no Spearman correlation significance. The results also show that the positive Spearman correlation was observed between asymmetry and participation.
\end{abstract}

Keywords: Budget slack. Information asymmetry. Participation budget. Budget risk decision. 


\section{INTRODUÇÃO}

O orçamento é uma das técnicas utilizadas pelos gerentes para o planejamento e controle das empresas. Hansen e Mowen (2001, p. 246) mencionam que o orçamento "[...] é um processo de traduzir as metas $\mathrm{e}$ as estratégias de uma organização em termos operacionais" e, quando utilizado para o controle empresarial, traduz-se como o “[...] processo de estabelecer padrões, receber feedback sobre o desempenho real e tomar as ações corretivas quando o desempenho real desviar-se significativamente do desempenho planejado".

Contribuindo a esse respeito, Anthony e Govindarajan (2001) ressaltam que o uso de um orçamento tem quatro finalidades principais: (1) dar forma pormenorizada ao plano estratégico; (2) auxiliar a coordenação das várias atividades da organização; (3) definir as responsabilidades dos executivos, autorizar limites de gastos e informá-los do desempenho que se espera; (4) ter o reconhecimento de que o orçamento é o instrumento de avaliação do real desempenho dos gestores.

Segundo Garrison e Noreen (2001), o orçamento proporciona os seguintes benefícios: (a) proporciona uma forma de comunicação gerencial acerca dos planos da empresa; (b) estimula os gerentes a pensar sobre as ações para o futuro da empresa, evitando gastos e esforços desnecessários; (c) promove um meio de alocar recursos entre os departamentos e as áreas; (d) evita a possibilidade do surgimento de potenciais restrições; (e) promove a integração dos planos das várias áreas da empresa e contribui para que esses planos trabalhem na mesma direção; (f) define metas e objetivos da empresa, servindo como benchmarks para futura avaliação de desempenho.

O orçamento normalmente não é um evento único, mas, sim, um processo que se repete em períodos sucessivos. Além disso, os orçamentos geralmente são definidos por meio de um processo de negociação entre a média gerência e a gerência superior, no qual os gerentes superiores têm uma grande influência, se não um controle completo, em relação ao orçamento final

(ANTHONY; GOVINDARAJAN, 2001).

$\mathrm{Na}$ elaboração do orçamento empresarial, algumas variáveis, tais como folga orçamentária, assimetria da informação, participação orçamentária, risco na decisão orçamentária, aversão à perda, ambiguidade da informação, podem influenciar na sua composição, interferindo na decisão dos gerentes.

Ho e Vera-Muñoz (2001) destacam que a média gerência pode priorizar seus 
departamentos, apresentando interesses que divergem dos interesses da gerência superior. Essa divergência de interesses pode causar algumas dificuldades para a empresa no caminho para o alcance de suas metas, como a folga orçamentária (MAIGA; JACOBS, 2007)

Para Anthony e Govindarajan (2001), a média gerência, com o intuito de se proteger contra eventuais incertezas do mercado, procura orçar receitas um pouco mais baixas e despesas um pouco mais altas do que as corretas, no momento da elaboração do orçamento, tornando as metas mais fáceis de serem alcançadas.

Tendo como base as pesquisas que estudam as variáveis que podem influenciar a decisão dos gerentes no momento da elaboração do orçamento, questiona-se: qual a relação entra a folga orçamentária, a assimetria da informação, a participação orçamentária e o risco?

A partir do problema de pesquisa, elaborou-se o objetivo geral do estudo, que consiste em verificar a relação da assimetria da informação, da participação orçamentária e da posição de risco na criação da folga orçamentária da média gerência de organizações. Desse modo, buscaram-se alunos de cursos de pósgraduação lato sensu nas áreas de Contabilidade e Administração em instituições de ensino do estado de Santa Catarina que se enquadravam na condição de gerência.

Sendo o orçamento e a sua elaboração uma das decisões mais relevantes para o mundo empresarial, justifica-se o estudo, pois o orçamento, elaborado de forma inadequada, pode influenciar o desempenho da empresa de modo a proporcionar aplicação de recursos de forma imprópria, podendo resultar em perdas de oportunidades e competitividade. $\mathrm{O}$ estudo se torna relevante também pelo fato de o tema folga orçamentária relacionada com a assimetria da informação, a participação orçamentária e o risco no orçamento - não ter sido explorado em pesquisas no Brasil. Os temas vêm sendo estudados mais frequentemente na literatura internacional, fazendo surgir o interesse em abordá-los com os gerentes das organizações nacionais.

\section{REVISÃO DE LITERATURA}

Este tópico apresenta a revisão teórica da pesquisa, incluindo a caracterização e os conceitos sobre a folga orçamentária, a assimetria da informação, a participação orçamentária e o posicionamento de risco do gestor quanto ao orçamento.

\subsection{Folga Orçamentária}


A folga orçamentária é definida por Young (1985) como o montante pelo qual a média gerência subestima sua capacidade produtiva, quando dada a oportunidade de selecionar um padrão de trabalho contra o qual seu desempenho será avaliado pela gerência superior.

Para Anthony e Govindarajan (2001), a gerência superior é constituída por executivos da alta administração da empresa, cabendo-lhes as funções de planejamento estratégico da organização, que englobam a definição de objetivos, metas e estratégias. Conforme os autores, esses executivos têm a função de analisar o ambiente externo da empresa, de investigar as tendências e de obter meios para poder tornar sua empresa competitiva no mercado, buscando se inserir no mercado ou aumentar seu campo de atuação. Já os executivos da média gerência, conforme os autores, são os responsáveis por áreas ou departamentos da empresa, cabendo-lhes a tomada das decisões sobre as ações que se referem especificamente às suas áreas de responsabilidade.

Quando a média gerência cria a folga, ela explora seus conhecimentos sobre as possibilidades de negócios da empresa e também acerca do estabelecimento de metas de desempenho deliberadamente inferior ao seu melhor palpite sobre a previsão de futuro dos negócios da empresa, segundo Lukka (1988).

A folga protege contra imprevistos e contingências, aumenta a probabilidade de cumprimento do objetivo, ampliando assim a chance de o gerente receber uma avaliação positiva e as recompensas associadas ao desempenho esperado. Van der Stede (2000) ressalta que a média gerência constitui a folga como um meio de proteção contra uma avaliação negativa futura, principalmente nas empresas que tratam do orçamento como um forte compromisso do gerente para com a corporação, e usa o orçamento como forma de avaliar a gestão de desempenho do gestor.

A folga proporciona uma proteção contra a incerteza por meio da disponibilidade de recursos livres criados com ela (MERCHANT, 1985). O autor ressalta que os recursos da folga permitem aos gerentes experimentar de modo seguro, por exemplo, a introdução de novos produtos ou a introdução de produtos inovadores. Bourgeois (1981) destaca que a folga pode apresentar aspectos positivos, pois os recursos provenientes de sua criação fornecem uma almofada para apoiar a exploração de oportunidades de mercado e uma fonte de recursos para experimentar na inovação de novos produtos. 
O principal argumento para os esforços dos gerentes para a construção da folga em seus orçamentos é melhorar as perspectivas de sua remuneração, conforme Dunk (1993). O autor ressalta que quando a média gerência percebe que suas recompensas dependem da realização das metas orçamentárias, ela pode tentar construir a folga em seu orçamento, o que lhe permite alcançar mais facilmente suas metas.

Assim, a média gerência pode ter interesses que divergem dos interesses da gerência superior e da empresa em geral, segundo Ho e Vera-Muñoz (2001). A média gerência, no intuito de atender os seus objetivos, pode tomar decisões que maximizem os seus interesses, valorizando o próprio bem-estar, em detrimento dos interesses da alta administração ou da própria empresa. Os autores destacam, como exemplo, que a média gerência pode preferir aumentar o tamanho do seu departamento a incrementar os lucros da empresa. Com esse comportamento, a média gerência interfere no objetivo final da empresa.

Em empresas descentralizadas, Ho e Vera-Muñoz (2001) destacam que a gerência superior está fisicamente separada da média gerência. Esse fato pode interferir na gestão, causando alguns problemas, tais como: 1) dificuldade das gerências superior e média de elaborar um mapeamento direto de todas as possibilidades em caso de decisões complexas e incertas, pela falta de interação entre os gerentes, que não permite troca de informações e dificulta a análise dessas possibilidades e dos resultados de suas ações; 2) impossibilidade da gerência superior, devido ao distanciamento, de observar o esforço de gestão da média gerência, analisando seu desempenho somente através dos resultados finais do departamento e não analisando suas ações; 3) dificuldade da gerência superior, sem acompanhar o departamento, de obter medidas confiáveis sobre a performance da média gerência.

Com esse distanciamento entre as gerências superior e média e tendo seu desempenho avaliado através do orçamento, a média gerência se cerca de meios de proteção para que possa atingir suas metas de forma mais segura, evitando, assim, penalizações e recebendo recompensas pelo sucesso no cumprimento dos objetivos.

\subsection{Assimetria da Informação}

A assimetria da informação "[...] tem-se concentrado nos problemas causados por informação incompleta, ou seja, quando nem todos os estados são conhecidos por ambas as partes e, assim, 
certas consequências não são por elas consideradas". Por exemplo, “[...] os proprietários podem não saber quais são as preferências dos administradores, o que dificulta a realização do cálculo mencionado" (HENDRIKSEN; VAN BREDA, 1999, p. 139).

A assimetria da informação só existe quando a média gerência dispõe de mais informações do que a gerência superior. Por ser conhecedora de todo o processo da empresa e participar do dia a dia da instituição, a média gerência pode dispor de informações das quais o seu superior não dispõe. Com essas informações privilegiadas, o gerente médio pode buscar benefícios pessoais ou benefícios para seu departamento no momento da elaboração do orçamento. Uma das maneiras de a gerência superior obter essas informações que estão de posse da média gerência é incentivar essa média gerência a compartilhar do processo de definição do orçamento. A participação orçamentária permite que a média gerência possa se comunicar ou revelar algumas de suas informações privadas, que podem ser incorporadas às normas ou aos orçamentos (DUNK, 1993).

Young (1985) destaca, porém, que mesmo participando do processo orçamentário, a média gerência pode reter informações privadas, o que poderia levar à folga orçamentária. Mesmo assim, o autor destaca que a participação orçamentária é a melhor forma que a gerência superior dispõe de obter as informações privadas em posse do gerente médio. Young (1985) ressalta que, com a assimetria da informação, a folga pode aumentar nos orçamentos, principalmente nas empresas em que o orçamento tem ênfase elevada.

Hendriksen e Van Breda (1999, p. 139) afirmam que "[...] a informação é uma das maneiras de reduzir a incerteza, dando aos contadores papel importante na divisão de riscos entre administradores e proprietários". Chow, Cooper e Waller (1988) mencionam que se houver uma boa comunicação entre a média gerência e a superior, os recursos da empresa podem ser melhor aplicados, proporcionando maior retorno financeiro para a corporação.

\subsection{Participação Orçamentária}

A participação orçamentária, para Anthony e Govindarajan (2001, p. 476), é “[...] um processo em que o pessoal do setor orçado é envolvido e influencia a definição dos valores do orçamento". Para Kim (1992), a participação orçamentária se refere a um estilo específico de gestão em que a média gerência está autorizada a participar com a gerência superior na definição do orçamento empresarial. 
Conforme Milani (1975), a participação é o conceito usado para descrever até que ponto a média gerência está autorizada a selecionar seus próprios cursos de ação do seu departamento. Young (1985) define a participação como um regime orçamentário em que a média gerência seleciona as metas de desempenho em conjunto com a gerência superior.

Para Shields e Shields (1998), o processo de participação orçamentária é aquele em que a média gerência participa na elaboração do planejamento orçamentário e tem influência na definição do seu próprio orçamento. Os autores mencionam que a participação ocorre com o intuito de: a) trocar informações entre as gerências superior e média da empresa; b) coordenar interdependências; c) motivar e promover atitudes, proporcionando inclusive a redução da tendência de criar a folga orçamentária (SHIELDS; YOUNG, 1993; SHIELDS; SHIELDS, 1998). Baiman (1990) afirma que a participação da média gerência no processo orçamentário pode diminuir a assimetria da informação, aprimorando a comunicação entre a gerência superior e a média, proporcionando melhor alocação dos recursos financeiros da empresa.

A participação no orçamento, para Young (1985), permite à média gerência trazer informações que possam aperfeiçoar os padrões de desempenho do seu departamento, aprimorando, dessa forma, a criação de mais empregos $\mathrm{e}$ proporcionando maior satisfação no trabalho. Segundo o autor, devido à média gerência estar diretamente relacionada com as atividades da empresa, essa gerência pode obter algumas informações privadas que, se devidamente exploradas, podem aumentar a produtividade corporativa.

Conforme Kyj e Parker (2008), essas informações são privadas no sentido de que a gerência superior não pode obtêlas ou somente pode acessá-las incorrendo em custos significativos. Para os autores, o grau de informação privada está relacionado à assimetria de informação entre a gerência superior e a média em relação ao conhecimento da área de operação da média gerência. Com a participação no processo orçamentário, a média gerência pode revelar suas informações privadas, melhorando o seu desempenho e os ganhos financeiros da empresa.

Também, a participação orçamentária pode levar à redução da folga, o que pode ser atribuído à comunicação positiva entre a gerência superior e a média, fazendo com que a média gerência se sinta mais tranquila em relação aos resultados, pois, participando do processo orçamentário, ela toma parte nas decisões, diminuindo a necessidade da 
criação da folga orçamentária (MERCHANT, 1985).

Dunk (1993) ressalta que, com a participação orçamentária, as gerências superior e média comunicam-se mais, compartilhando as informações, podendo desenvolver as metas orçamentárias de forma mais concisa, pois contam com informações de melhor qualidade.

\subsection{Risco na Decisão Orçamentária}

A média gerência se esforça para evitar o não cumprimento das metas estabelecidas pelas empresas e busca recompensas pelo sucesso do alcance das metas (HO; VERA-MUÑOZ, 2001). Conforme os autores, a média gerência estabelece como principal foco evitar ações que a coloque abaixo das metas estipuladas pela empresa, analisando cuidadosamente o risco que os projetos orçados podem apresentar.

Ho e Vera-Muñoz (2001) salientam que a média gerência também pode alterar a análise do risco que a envolve na elaboração do orçamento, com base em experiências passadas. Conforme os autores, o desempenho passado dessa gerência pode afetar o comportamento e as decisões no futuro, limitando as suas ações baseadas em fatos ocorridos, evitando o alto grau de exposição e procurando projetos que possam diminuir o seu risco perante a elaboração do orçamento empresarial.

O comportamento dos indivíduos e as suas ações se alteram após eles terem experimentado um sucesso ou um fracasso. Uma explicação é que indivíduos que se sentem responsáveis por ter provocado um resultado indesejável ficam angustiados perante resultados insatisfatórios. Para tentar reduzir essa angústia, os indivíduos intensificam os seus esforços para restabelecer a sua competência, buscando demonstrar as suas qualidades aos seus superiores, objetivando projetar uma imagem de bom funcionário (HO; VERAMUÑOZ, 2001).

Com as experiências bem ou malsucedidas no passado, os gerentes podem desenvolver temores e restrições em relação ao processo orçamentário, podendo criar uma aversão ao risco e à perda. Sullivan e Kida (1995) mencionam que as pesquisas sobre aversão à perda sugerem que a média gerência, cujos departamentos geralmente realizam metas acima de um determinado alvo no passado, busca evitar ações que possam colocar esses departamentos abaixo da meta para o futuro. Johnston e Kim (1994) afirmam que a aversão à perda pode afetar o comportamento futuro, pois as experiências exitosas ou fracassadas vivenciadas por um gerente podem afetar o comportamento e as expectativas para seu 
futuro desempenho.

Em geral, os resultados abaixo da meta são avaliados como perdas e os resultados acima da meta, como ganhos. Normalmente, as perdas parecem psicologicamente maiores, sendo evitadas de todas as formas nas empresas. Em contrapartida, quando as metas são superadas, tornam-se marcas dos responsáveis pelos resultados, dando-lhes moral na empresa (KIM, 1992). Indivíduos que têm aversão ao risco preferem sempre os orçamentos de segurança aos orçamentos apertados. Já os sujeitos que não têm aversão ao risco preferem os orçamentos apertados em vez dos orçamentos de segurança, independentemente do seu desempenho em relação ao desempenho médio de outros indivíduos.

Em estudo desenvolvido por Young (1985), o autor teve como objetivo testar, empiricamente, os efeitos das informações privadas sobre a capacidade produtiva, as preferências de risco e a participação na folga orçamentária num período único em que houve o estudo experimental. Cinco hipóteses relacionadas com a folga orçamentária foram desenvolvidas e testadas: Hipótese 1 - a média gerência que participa do processo orçamentário vai criar a folga no orçamento; Hipótese 2 - a média gerência com aversão ao risco vai criar mais folga no orçamento do que a média gerência sem aversão ao risco; Hipótese 3 - a pressão social para não deturpar a capacidade produtiva será maior para a média gerência, cuja informação é conhecida pela gerência superior, do que para a média gerência com informação privada; Hipótese 4 - à medida que aumenta a pressão social para a média gerência, há menor grau de folga orçamentária; Hipótese $5-$ a média gerência, que tem a informação privada, estabelece mais folga no orçamento do que a média gerência cuja informação é conhecida pela gerência superior.

Para participar da pesquisa, foram selecionados 40 estudantes do curso de Mestrado em Administração de Negócios (sigla inglesa MBA), separados em dois grupos de 20 pessoas, estando um grupo com assimetria da informação e o outro não. Para mensurar a disposição dos participantes perante o risco, Young (1985) desenvolveu a seguinte questão: eu estou disposto a oferecer uma proposta em que você recebe $\$ 5,00$ de certeza ou fazer uma aposta em que você pode receber $\$ 10,00$, tendo $\mathrm{X}$ de chance de isso ocorrer e (1-X) de chance de receber $\$ 0,00$. Qual o valor para $X$ (entre 0 e 1) para que você seja indiferente aos $\$ 5$ e decida fazer a aposta? a) mais de 0,$50 ;$ b) menos de 0,50 .

Os resultados da pesquisa confirmaram a hipótese de que a média gerência participante do processo 
orçamentário cria folga orçamentária e que a folga é em parte atribuível às preferências de um gerente que escolhe o risco. Além disso, embora a posse de informações dê uma oportunidade à média gerência de melhorar sua capacidade produtiva, essa oportunidade é mitigada pela pressão social para revelar as informações. Curiosamente, a medida da pressão social esteve altamente correlacionada com a quantidade de folga. A pesquisa demonstrou também que, embora a quantidade média de folga criada pelas informações privadas não tenha sido significativamente diferente em relação à média gerência que não tinha as informações privadas, a média gerência com informações privadas demonstrou uma maior variação na produção de folga sobre a capacidade produtiva.

\subsection{Estudos Recentes}

Este item apresenta estudos recentes que pesquisaram as variáveis estudadas - folga orçamentária, assimetria da informação, participação orçamentária e riscos no orçamento - e as compararam com outras variáveis. Em estudo realizado por Van der Stede (2000), foi examinado se existem efeitos indiretos entre duas supostas consequências disfuncionais de um estilo rígido de controle orçamentário: a criação de folga orçamentária e a orientação gerencial para investimentos de curto prazo. Para atingir os seus objetivos, o autor desenvolveu as hipóteses: H1 - os controles orçamentais rígidos são: a) negativamente relacionados com folga orçamentária e b) positivamente relacionados com a orientação de gestão de curto prazo; $\mathrm{H} 2$ - a folga orçamentária e a orientação de gestão de curto prazo são negativamente relacionadas; H3 - em relação às estratégias de liderança de custos, as diferenciações estratégicas são: a) negativamente associadas com os rígidos controles orçamentários e b) positivamente associadas com a folga orçamentária; H4 - o desempenho passado da unidade de negócio é: a) negativamente relacionado à rigidez dos controles orçamentários, b) positivamente relacionado com a folga orçamentária e c) negativamente relacionado à orientação de gestão de curto prazo.

Os dados foram coletados como parte de um estudo que investiga $o$ controle em grandes e diversificadas empresas com sede na Bélgica. $\mathrm{O}$ questionário foi desenvolvido e enviado à média gerência das unidades. No total, 341 questionários foram enviados em 1996 e 190 deles respondidos, dos quais 37 não puderam ser aproveitados, perfazendo um total de 153 respostas utilizadas na pesquisa. 
Os resultados demonstraram que existe relação negativa e significante entre os controles orçamentários rígidos e a folga orçamentária. A relação entre os controles orçamentários rígidos e a orientação de gestão de curto prazo não foi significante. A relação entre a folga orçamentária e a orientação de gestão de curto prazo foi significante e negativa, o que era esperado pelos autores. Essas correlações sugerem que os controles orçamentários rígidos reduzem a folga orçamentária. A redução da folga amplia a dificuldade de alcance das metas orçamentárias a curto prazo, aumentando a preocupação dos gerentes em relação às ações a serem tomadas a curto prazo para não prejudicar os resultados.

Os resultados da pesquisa de Van der Stede (2000) sugerem que o desempenho passado foi negativamente relacionado com a rigidez do controle orçamentário, positivamente relacionado com a folga e negativamente relacionado com a orientação de gestão a curto prazo. Os resultados apontam que a média gerência, mediante os controles orçamentários rígidos, tem menos margem de manobra para construir a folga orçamentária.

Webb (2002) analisou o impacto de dois elementos do contexto organizacional em decisões orçamentárias: a reputação e a análise de desvios orçamentários. Os resultados da análise denotaram que a preocupação com a manutenção da reputação favorável leva à menor folga orçamentária e à existência de uma política de análise de desvios. Os resultados incorporam tanto características pecuniárias quanto não pecuniárias, as quais influenciam o comportamento quando os orçamentos têm consequências além do período em vigor.

Adnan e Sulaiman (2007) investigaram os determinantes da propensão para a criação de folga, tendo analisado três perspectivas: organizacionais, culturais e religiosas. Especificamente, o estudo investigou como a participação orçamentária, a ênfase orçamentária, a disponibilidade de detecção de folga, o individualismo e a religião influenciaram na criação da folga orçamentária.

Do ponto de vista organizacional, examinaram três variáveis: a ênfase orçamentária, a participação e a disponibilidade de um sistema de detecção de folga. Em relação à perspectiva cultural, utilizaram o sistema de valores culturais de Hofstede para examinar a criação de folga orçamentária. No que concerne à folga orçamentária, examinaram se a religião e a religiosidade afetaram a criação da folga.

Os dados foram coletados por meio de um questionário e de entrevistas 
pessoais. Foram enviados questionários a 91 gerentes de uma empresa coreana com base na Malásia, dos quais 64 participaram da pesquisa.

Os resultados do estudo revelaram que a participação orçamentária, em conjunto com a ênfase orçamentária, influenciou na criação de folga orçamentária. Conforme os resultados, quando o orçamento tem ênfase elevada na empresa, a média gerência, mesmo participando do processo orçamentário, tem a propensão para criar a folga orçamentária, buscando, assim, atingir as suas metas de forma mais tranquila. Os resultados não evidenciaram que as variáveis de cultura nacional, a presença de um sistema de detecção de folga e a religião influenciaram na propensão de um gerente na criação da folga orçamentária.

A assimetria da informação, por meio da ambiguidade das informações, foi investigada por Ho, Keller e Keltyka (2002). Os autores buscaram analisar como essa ambiguidade influenciou os gerentes nas suas decisões. Buscaram, também, demonstrar que a aversão à ambiguidade é um fator comportamental e que há casos em que os gerentes estão propensos a ela. Trinta e nove alunos de MBA de uma universidade participaram do experimento e estavam matriculados em um curso de Contabilidade Gerencial. Os participantes tinham em média 3,4 anos de experiência nas empresas. Os resultados da pesquisa indicaram que a maioria dos gerentes está propensa à ambiguidade na condição de perda e passaram à aversão a ela na condição de ganho.

Parker e Kyj (2006) desenvolveram um modelo de partilha de informação vertical entre a gerência superior e a média no processo orçamentário. Os autores testaram uma relação direta entre a participação orçamentária e o compartilhamento de informações com a gerência superior. Analisaram as variáveis participação orçamentária, comprometimento organizacional, intercâmbio de informações entre as gerências superior e média e a ambiguidade.

Para participar da pesquisa, foram selecionadas 19 empresas afiliadas a uma escola de negócios das quais 13 participaram da pesquisa. Para as empresas participantes, os executivos foram convidados a distribuir os questionários aos gerentes e supervisores que tinham responsabilidades sobre $\mathrm{o}$ processo orçamentário. No total, 74 pessoas responderam o questionário.

Os resultados da pesquisa esclareceram que o compartilhamento de informações vertical é uma importante variável na compreensão dos efeitos do desempenho da participação orçamentária e do comprometimento organizacional. No 
que diz respeito à comunicação da média gerência e da gerência superior, os resultados revelaram uma significativa e positiva associação entre a partilha da informação e os antecedentes propostos: a participação orçamentária e o comprometimento organizacional. Os resultados demonstraram, ainda, que a partilha da informação está associada com o desempenho do trabalho individual. Em relação à comunicação entre as gerências média e superior, os resultados apontaram que, mesmo com a participação orçamentária, houve ambiguidade nas informações.

Kyj e Parker (2008) analisaram as causas ou os antecedentes e o papel da participação orçamentária. A pesquisa baseou-se nas razões que a gerência superior tem para incentivar a participação da média gerência no processo orçamentário, fundamentando-se em várias teorias, incluindo a teoria da liderança, a da agência e da justiça organizacional.

Para atingir os objetivos da pesquisa, os autores desenvolveram as hipóteses: H1 - o estilo de liderança da gerência superior tem relação positiva com o incentivo do gerente superior à participação orçamentária da média gerência; H2 - o incentivo da gerência superior à participação no orçamento está positivamente relacionado com a participação da média gerência no processo orçamentário; $\mathrm{H} 3$ - a assimetria da informação tem relação positiva com o incentivo da gerência superior à participação no orçamento; H4 - o uso do orçamento para avaliar o desempenho da média gerência tem relação positiva com o incentivo da gerência superior à participação no orçamento.

Para investigar as relações propostas para a pesquisa, um questionário foi distribuído em 13 empresas, e 70 gerentes e supervisores responderam à pesquisa. Os entrevistados trabalhavam nas mais diversas áreas, incluindo contabilidade, finanças, recursos humanos, operações e produção, e a maioria deles se descreveu como média ou superior gerência.

Os resultados da pesquisa de Kyj e Parker (2008) evidenciaram que a gerência superior incentiva a participação da média gerência no processo orçamentário quando o estilo de liderança da gerência superior é atenciosa. Os resultados também apontaram que a gerência superior incentiva a participação da média gerência no orçamento quando as metas orçamentárias são utilizadas para avaliar o desempenho da média gerência. $\mathrm{O}$ estudo argumenta também que a gerência superior incentiva a participação por causa da preocupação acerca da justiça organizacional. A relação proposta entre a 
assimetria da informação e a participação do orçamento não é suportada.

$$
\text { Ho e Vera-Muñoz }
$$
analisaram se a média gerência é influenciada pela aversão à perda no momento das suas recomendações para investimentos de capital na elaboração do orçamento. Para tanto, desenvolveram a seguinte questão problema: a média gerência é mais propensa a fazer recomendações de investimentos de capital quando o desempenho passado de seu departamento está acima da meta determinada ou quando o desempenho passado está inferior à meta predeterminada?

Para atingir seus objetivos, elaboraram as seguintes hipóteses testadas: H1 - a média gerência com alto desempenho é mais propensa a recomendar investimentos de capital a curto prazo, em detrimento da valorização da empresa a longo prazo, do que a média gerência com baixo desempenho; H2 - a média gerência com baixo e alto desempenho é mais propensa a recomendar investimentos de capital que maximizem os lucros de seu departamento a curto prazo quando o desempenho passado foi influenciado por fatores externos ou quando o desempenho passado foi influenciado por fatores internos; H3 - a tendência para recomendar investimentos de capital que maximizam lucros a curto prazo, em detrimento da valorização da empresa a longo prazo, será maior para a média gerência com baixo desempenho do que para a média gerência com alto desempenho.

Noventa e três alunos de graduação de uma universidade do oeste dos Estados Unidos, matriculados em um curso de Contabilidade Gerencial, participaram do experimento em sala de aula. Os participantes assumiram o papel de um gerente de um dos departamentos de operações de uma grande usina de papel. A principal tarefa consistiu em fazer uma recomendação à gerência superior quanto à possibilidade de substituir uma máquina a ser usada no negócio. Durante o processo, os partícipes foram recebendo mais informações para o desenvolvimento da pesquisa.

Os resultados da investigação sugerem que a média gerência com baixo desempenho, em geral, atribuiu as suas dificuldades aos fatores externos, não assumindo as responsabilidades pelas falhas de seu departamento. Em contraste, a média gerência com alto desempenho, em geral, responsabilizou os fatores internos pelos seus resultados, levando os créditos do sucesso de seu departamento, destacando-se a sua capacidade gerencial e seu esforço. Os resultados demonstraram, também, que tanto os fatores externos quanto os internos são utilizados pela 
média gerência na atribuição do desempenho de seus departamentos, e que esses fatores influenciaram as suas recomendações de investimentos de capital.

Os resultados ainda comprovaram que a média gerência foi mais propensa a recomendar investimentos de capital que beneficiassem os lucros a curto prazo, em detrimento da valorização da empresa a longo prazo. A média gerência também é mais propensa a recomendar investimentos a curto prazo quando o desempenho passado foi influenciado por fatores externos. Os resultados de Ho e VeraMuñoz (2001) ressaltaram que a experiência de gestão da média gerência não interferiu nas recomendações de investimento de capital. Os resultados apontaram que a média gerência com alto desempenho é mais propensa a propor investimentos que maximizem os lucros a curto prazo do que a média gerência com baixo desempenho.

Sprinkle, Williamson e Upton (2008) investigaram como contratos com base em orçamento afetam o esforço e o risco do indivíduo na tomada de decisões. Participaram da pesquisa sessenta alunos de graduação de um curso em negócios. Os participantes foram distribuídos aleatoriamente em dois grupos. $\mathrm{O}$ experimento consistiu em duas atividades principais: na primeira atividade, os participantes trabalharam determinado tempo em tarefas intensivas e, na segunda, escolheram jogar um dos doze jogos possíveis que variaram em risco e retorno esperado.

Os resultados da pesquisa atestaram que os indivíduos estão dispostos a sacrificar a riqueza esperada para cumprir o orçamento ou aumentar os seus resultados potenciais. Os resultados sugerem que a troca de risco é alterada pelo esforço em níveis de orçamentos baixos, aumentando assim o bem-estar da empresa, mas é agravada em orçamento de níveis elevados, reduzindo o bem-estar empresarial. Os autores destacam que a média gerência prefere orçamentos mais apertados quando tem direito de participar do processo orçamentário e da definição do orçamento final. Os resultados ressaltam que o orçamento afeta alguns determinantes do desempenho do gerente quando esse desempenho é avaliado através do orçamento.

Em um estudo numa filial brasileira de uma empresa multinacional, Lavarda e Almeida (2013) procuraram verificar a influência da participação orçamentária na redução da assimetria da informação. Os autores realizaram um estudo de caso, por meio de entrevistas e observação com os gerentes departamentais da filial, concluindo que a unidade de negócios realizava encontros formais de discussão 
das metas orçamentárias, porém a assimetria da informação entre a média gerência e a gerência superior permanecia presente na organização.

\section{METODOLOGIA}

A pesquisa caracteriza-se como descritiva. Cervo e Bervian (2002, p. 66) mencionam que "[...] a pesquisa descritiva observa, registra, analisa e correlaciona fatos ou fenômenos (variáveis) sem manipulá-los".

Quanto à abordagem do problema, o estudo é de natureza quantitativa. Segundo Richardson (1989, p. 29) a pesquisa quantitativa “[...] caracteriza-se pelo emprego da quantificação tanto nas modalidades de coleta de informações quanto no tratamento desses dados através de técnicas estatísticas desde as mais simples às mais complexas, como coeficiente de correlação, análise de regressão, etc.”.

Quanto aos procedimentos, a pesquisa classifica-se como levantamento ou survey. Para Gil (1999, p. 70), as pesquisas de levantamento "[...] se caracterizam pela interrogação direta das pessoas cujo comportamento se deseja conhecer".

Para a consecução dos objetivos da pesquisa, buscou-se a participação de indivíduos que atuam na gerência média em diversas organizações. Assim, definiuse como estratégia de coleta de dados, em primeiro lugar, a identificação de cursos de pós-graduação lato sensu oferecidos por instituições de ensino de Santa Catarina, na área de Ciências Contábeis e Administração, no período de dezembro de 2010 a maio de 2011, que concentram grande parte de alunos vinculados a diversas organizações comerciais e industriais, semelhantemente ao estudo de Ho, Keller e Keltyka (2002).

Em segundo lugar, por meio da identificação no questionário da função exercida pelos alunos desses cursos, selecionaram-se aqueles que se enquadravam no nível de gerência média, excluindo os que não trabalhavam ou exerciam funções de gerência superior.

Essa estratégia buscou aumentar o número de respondentes da pesquisa, de modo a facilitar a obtenção de dados diretamente com as empresas e a aumentar a validade dos constructos (MARTINS; THEÓPHILO, 2009).

Dessa forma, foram contatadas as instituições de ensino superior para que autorizassem a aplicação dos questionários. Em seguida, o pesquisador apresentou-se em cada sala de aula, apresentou o questionário e coletou os dados. O Quadro 1 apresenta os cursos e as cidades onde foram aplicados os questionários. 
Foram respondidos $\quad 379$ questionários, dos quais 171 compuseram a amostra da pesquisa, em que o cargo/função desempenhado pelo respondente se enquadrasse nas seguintes opções: supervisor, gerente administrativo, gerente financeiro, gerente de produção, gerente de recursos humanos, gerente comercial e outros, desde que fossem gerentes de departamento. Entre a opção outros, os respondentes destacaram que eram gerentes de negócios, de marketing, de unidade, de importação, de compras e negócios internacionais, de operações, de vendas, de PAC e de loja. Os 208 respondentes que marcaram como cargo/função as opções de proprietário/acionista, diretor, auxiliar administrativo e outros, que não se enquadrassem em nenhum cargo de gerente, não foram utilizados.

Quadro 1 - Cursos e cidades em que foram aplicados os questionários

\begin{tabular}{|c|c|}
\hline Curso & Cidade \\
\hline MBA Executivo Comércio Exterior e Logística Internacional & Blumenau \\
\hline MBA Executivo Gestão Comercial e Vendas & Blumenau \\
\hline MBA Executivo Gerenciamento de Marketing & Blumenau \\
\hline MBA Executivo Gestão da Produção e Operações & Blumenau \\
\hline MBA Executivo Logística Empresarial & Blumenau \\
\hline MBA Executivo Mercado de Capitais & Blumenau \\
\hline MBA Executivo Finanças e Controladoria & Blumenau \\
\hline MBA Executivo Cooperativas de Crédito & Blumenau \\
\hline MBA Executivo Gestão Hospitalar & Blumenau \\
\hline MBA Executivo Gestão Estratégica de Negócios & Blumenau \\
\hline MBA Executivo Gestão Estratégica de Varejo & Blumenau \\
\hline MBA Executivo Marketing e Criação de Moda & Blumenau \\
\hline MBA Finanças, Controladoria e Gestão Tributária & Blumenau \\
\hline MBA Executivo Gestão Tributária & Blumenau \\
\hline MBA Gestão Financeira e Controladoria & São Miguel do Oeste \\
\hline MBA Logística Empresarial & Xaxim \\
\hline MBA Finanças, Controladoria e Gestão Tributária & Chapecó \\
\hline Especialização Mercado de Capitais & Blumenau \\
\hline Especialização Gestão Estratégica de Negócios & Blumenau \\
\hline Especialização Contabilidade e Gestão Tributária & Blumenau \\
\hline Especialização Controladoria & Blumenau \\
\hline Especialização Gestão Tributária & Blumenau \\
\hline
\end{tabular}

Fonte: elaboração própria. 
$\mathrm{O}$ instrumento de pesquisa utilizado foi o questionário com questões fechadas, elaborado a partir das referências teóricas que tratam do tema. Após leitura das obras, extraiu-se o questionário dos estudos de forma que pudesse fornecer subsídios para alcançar o objetivo estabelecido para o estudo. O Quadro 2 mostra o constructo da pesquisa.

A escala de medição das variáveis foi do tipo Likert de 7 pontos, em que: Concordo Totalmente (CT) vale 7 pontos,
Concordo Moderadamente (CM) 6 pontos, Concordo Parcialmente (CP) 5 pontos, Neutro (N) 4 pontos, Discordo Parcialmente (DP) 3 pontos, Discordo Moderadamente (DM) 2 pontos, e Discordo Totalmente (DT) 1 ponto. O respondente deveria escolher somente uma opção, conforme os estudos base, para as questões de folga orçamentária, de assimetria da informação e de participação orçamentária.

Quadro 2 - Constructo da pesquisa

\begin{tabular}{|l|l|c|c|}
\hline Variáveis & \multicolumn{1}{|c|}{ Definição conceitual } & \multicolumn{1}{|c|}{ Questões } & \multicolumn{1}{|c|}{$\begin{array}{c}\text { Autores de } \\
\text { base }\end{array}$} \\
\hline $\begin{array}{l}\text { Caracterização } \\
\text { do orçamento }\end{array}$ & $\begin{array}{l}\text { Um orçamento é a expressão quantitativa de um plano de } \\
\text { Eçuturo da administração para um determinado período. } \\
\text { Elesse plano e funciona como um projeto a ser seguido pela } \\
\text { companhia em período vindouro. }\end{array}$ & 1 a 5 da parte A & $\begin{array}{l}\text { Anthony } \\
\text { Govindarajan } \\
(2001)\end{array}$ \\
\hline $\begin{array}{l}\text { Folga } \\
\text { orçamentária }\end{array}$ & $\begin{array}{l}\text { A folga de receita ocorre quando o orçamento subestima as } \\
\text { receitas versus as expectativas, enquanto folga de despesa } \\
\text { levaria a um exagero de gastos orçados versus } \\
\text { expectativas. }\end{array}$ & 1 a 6 da parte B & Dunk (1993) \\
\hline $\begin{array}{l}\text { Assimetria da } \\
\text { informação }\end{array}$ & $\begin{array}{l}\text { Problemas causados por informação incompleta, ou seja, } \\
\text { quando nem todos os estados são conhecidos por ambas as } \\
\text { partes e, assim, certas consequências não são por elas } \\
\text { consideradas. }\end{array}$ & 1 a 6 da parte C & Dunk (1993) \\
\hline $\begin{array}{l}\text { Participação } \\
\text { orçamentária }\end{array}$ & $\begin{array}{l}\text { O processo de participação orçamentária é aquele em que o } \\
\text { gestor participa na elaboração do planejamento } \\
\text { orçamentário e tem influência na definição do seu próprio } \\
\text { orçamento. }\end{array}$ & 2 a 6 da parte D & Milani (1975) \\
\hline $\begin{array}{l}\text { Risco na } \\
\text { decisão } \\
\text { orçamentária }\end{array}$ & $\begin{array}{l}\text { Os gestores estabelecem como principal foco evitar ações } \\
\text { que os coloquem abaixo das metas, analisando } \\
\text { cuidadosamente o risco que correm na elaboração do } \\
\text { orçamento. }\end{array}$ & 1 da parte E & Young (1985) \\
\hline
\end{tabular}

Fonte: elaboração própria.

Em relação ao risco no orçamento, a questão contemplava duas opções e somente uma a ser escolhida pelos respondentes, caracterizando a neutralidade ao risco se marcassem a opção A e a disposição ao risco se marcassem a opção B, conforme apresentado por Young (1985).

O questionário foi aplicado em sala de aula nos cursos de pós-graduação que 
tinham ligação com os cursos de Ciências Contábeis e Administração, por serem os cursos com maior participação de respondentes com condições de contribuir com o estudo.

O questionário foi composto por 6 partes e 31 questões no seu total, incluindo todas as 6 partes que buscam atingir os objetivos da pesquisa e testar as hipóteses. A primeira parte do questionário objetivou obter informações sobre o respondente, a saber: idade, gênero, nível de escolaridade, cargo/função desempenhado atualmente, tempo de atuação na empresa, tempo de atuação na função e quantidade de funcionários da empresa. A segunda parte buscou, por meio de cinco perguntas baseadas em Anthony e Govindarajan (2001), a caracterização do orçamento, objetivando assim obter a percepção dos respondentes. A terceira parte contempla seis questões sobre a folga orçamentária, com base no estudo de Dunk (1993). A quarta parte está composta de seis questões sobre a assimetria da informação, baseadas no estudo de Dunk (1993). Na quinta parte constam seis questões sobre a participação orçamentária com base no estudo de Milani (1975), e na sexta parte é mencionada uma questão sobre o risco na decisão orçamentária, proposta no estudo de Young (1985).

De posse dos dados, criou-se um banco de dados confeccionado a partir de uma planilha eletrônica, utilizado na importação dessas informações para o software SPSS ${ }^{\circledR} 20$, em que foram analisadas com o auxílio do teste de validade de escalas Alpha de Cronbach, da correlação de Spearman para dados não paramétricos e dos testes de MannWhitney e de Kruskal-Wallis.

A partir do exame da literatura, foram elaboradas três hipóteses de pesquisas a seguir descritas:

H1 - quanto maior a participação orçamentária da média gerência na elaboração do orçamento menor será a folga orçamentária.

H2 - quanto maior a assimetria da informação entre a média gerência e a gerência superior na elaboração do orçamento maior será a folga orçamentária. H3 - quanto maior for a neutralidade da média gerência em relação ao risco na elaboração do orçamento menor será a folga orçamentária.

\section{ANÁLISE DOS RESULTADOS}

Em relação à caracterização dos respondentes, a amostra é composta por $56,14 \%$ deles com idade até 30 anos, sendo $60,82 \%$ do gênero masculino e tendo $70,76 \%$ o nível de escolaridade especialização. Dos respondentes, 48,54\% trabalham na empresa até 4 anos, sendo $66,67 \%$ atuantes na mesma função no 
máximo há 3 anos e em empresas com até 99 funcionários, em 39,77\% das respostas.

A Tabela 1 apresenta as respostas do grupo de questões sobre a caracterização do orçamento nas organizações em que atuam os respondentes.

A Tabela 1 mostra, de forma geral, em relação ao grupo de questões referentes à caracterização do orçamento, percentual de concordância acima de $84 \%$ por parte dos respondentes com as características apontadas por Anthony e Govindarajan (2001).

\subsection{Análise da Folga Orçamentária}

Esta seção apresenta os resultados da pesquisa em relação às questões referentes à folga orçamentária. A Tabela 2 apresenta a quantidade de respostas obtidas em relação a essas questões.

Tabela 1 - Respostas do grupo de questões sobre a caracterização do orçamento

\begin{tabular}{|c|c|c|c|c|c|c|c|c|c|}
\hline \multicolumn{2}{|c|}{ Questões } & \multirow{2}{*}{$\begin{array}{c}\begin{array}{r}\text { DT } \\
\text { Resp. } \\
\text { \% }\end{array} \\
4 \\
2,34\end{array}$} & \multirow{2}{*}{$\begin{array}{c}\begin{array}{c}\text { DM } \\
\text { Resp. } \\
\text { \% }\end{array} \\
4 \\
2,34\end{array}$} & \multirow{2}{*}{$\begin{array}{c}\begin{array}{c}\text { DP } \\
\text { Resp. } \\
\%\end{array} \\
1 \\
0,58\end{array}$} & \multirow{2}{*}{$\begin{array}{c}\begin{array}{c}\mathbf{N} \\
\text { Resp. } \\
\%\end{array} \\
1 \\
0,58\end{array}$} & \multirow{2}{*}{$\begin{array}{c}\begin{array}{c}\text { CP } \\
\text { Resp. } \\
\text { \% }\end{array} \\
7 \\
4,09\end{array}$} & \multirow{2}{*}{$\begin{array}{c}\text { CM } \\
\text { Resp. } \\
\text { \% }\end{array}$} & \multirow{2}{*}{$\begin{array}{c}\begin{array}{c}\text { CT } \\
\text { Resp. } \\
\text { \% }\end{array} \\
130 \\
76,02\end{array}$} & \multirow{2}{*}{$\begin{array}{c}\begin{array}{c}\text { Total } \\
\text { Resp. } \\
\%\end{array} \\
171 \\
100,00\end{array}$} \\
\hline 1 & $\begin{array}{l}\text { O orçamento é um instrumento } \\
\text { importante para o planejamento e o } \\
\text { controle das empresas. }\end{array}$ & & & & & & & & \\
\hline 2 & $\begin{array}{l}\text { É um compromisso gerencial. Os } \\
\text { executivos comprometem-se a } \\
\text { aceitar a responsabilidade de atingir } \\
\text { os objetivos do orçamento. }\end{array}$ & $\begin{array}{c}7 \\
4,09\end{array}$ & $\begin{array}{c}2 \\
1,17\end{array}$ & $\begin{array}{c}8 \\
4,68\end{array}$ & $\begin{array}{c}4 \\
2,34\end{array}$ & $\begin{array}{c}32 \\
18,71\end{array}$ & $\begin{array}{c}64 \\
37,43\end{array}$ & $\begin{array}{c}54 \\
31,58\end{array}$ & $\begin{array}{c}171 \\
100,00\end{array}$ \\
\hline 3 & $\begin{array}{l}\text { A proposta orçamentária é aprovada } \\
\text { por autoridade mais alta do que os } \\
\text { responsáveis pela execução do } \\
\text { orçamento. }\end{array}$ & $\begin{array}{c}9 \\
5,26\end{array}$ & $\begin{array}{c}5 \\
2,92\end{array}$ & $\begin{array}{c}11 \\
6,44\end{array}$ & $\begin{array}{c}9 \\
5,26\end{array}$ & $\begin{array}{c}35 \\
20,47\end{array}$ & $\begin{array}{c}43 \\
25,15\end{array}$ & $\begin{array}{c}59 \\
34,50\end{array}$ & $\begin{array}{c}171 \\
100,00\end{array}$ \\
\hline 4 & $\begin{array}{l}\text { Uma vez aprovado, o orçamento só } \\
\text { poderá ser alterado sob condições } \\
\text { especiais (ex: oportunidades de } \\
\text { mercado). }\end{array}$ & $\begin{array}{c}14 \\
8,19\end{array}$ & $\begin{array}{c}11 \\
6,44\end{array}$ & $\begin{array}{c}12 \\
7,02\end{array}$ & $\begin{array}{c}6 \\
3,51\end{array}$ & $\begin{array}{c}43 \\
25,15\end{array}$ & $\begin{array}{c}45 \\
26,30\end{array}$ & $\begin{array}{c}40 \\
23,39\end{array}$ & $\begin{array}{c}171 \\
100,00\end{array}$ \\
\hline 5 & $\begin{array}{l}\text { O desempenho financeiro real é } \\
\text { comparado com o orçamento e as } \\
\text { variações são analisadas e } \\
\text { explicadas. }\end{array}$ & $\begin{array}{c}3 \\
1,75\end{array}$ & $\begin{array}{c}3 \\
1,75\end{array}$ & $\begin{array}{c}4 \\
2,34\end{array}$ & $\begin{array}{c}16 \\
9,36\end{array}$ & $\begin{array}{c}31 \\
18,13\end{array}$ & $\begin{array}{c}45 \\
26,30\end{array}$ & $\begin{array}{c}69 \\
40,37\end{array}$ & $\begin{array}{c}171 \\
100,00\end{array}$ \\
\hline \multicolumn{2}{|c|}{$\begin{array}{l}\text { Total } \\
\text { Percentual }\end{array}$} & $\begin{array}{r}37 \\
4,33 \\
\end{array}$ & $\begin{array}{c}25 \\
2,92\end{array}$ & $\begin{array}{c}36 \\
4,21 \\
\end{array}$ & $\begin{array}{c}36 \\
4,21 \\
\end{array}$ & $\begin{array}{c}148 \\
17,31 \\
\end{array}$ & $\begin{array}{c}221 \\
25,85\end{array}$ & $\begin{array}{c}352 \\
41,17 \\
\end{array}$ & $\begin{array}{c}855 \\
100,00\end{array}$ \\
\hline
\end{tabular}

Fonte: dados da pesquisa.

As questões sobre a folga orçamentária apresentam escala reversa, na qual as questões 1,3 e 6 indicam a folga quando as respostas compreendem as opções discordo parcialmente a totalmente. As questões 2, 4 e 5 estão em sentido contrário, indicando a folga se as respostas forem nas opções concordo parcialmente a totalmente (Tabela 2).

Quanto às questões 1,3 e 6 , os resultados apontam predomínio das respostas nas opções concordo 
parcialmente a totalmente, cuja soma alcança 71,73\%. Em relação às questões 2, 4 e 5, os resultados indicam pouca distinção entre as opções discordo $(42,69 \%)$ e concordo $(50,5 \%)$, porém com baixo predomínio nas opções concordo. Com os resultados dessas questões, não se pode afirmar que existe folga orçamentária nas empresas em que os respondentes atuam.

Foi realizado o teste de MannWhitney da variável gênero em relação às questões referentes à folga orçamentária, porém não apresentou significância em nível de 5\%. Os resultados do teste de Kruskal-Wallis demonstraram que a variável nível de escolaridade não apresentou significância em nível de 5\% para nenhuma questão referente à folga orçamentária. A variável tempo de atuação na empresa apresentou significância na questão 5. A variável tempo na função apresentou significância nas questões 4 e 5.

Tabela 2 - Quantidade de respostas do grupo de questões sobre a folga orçamentária

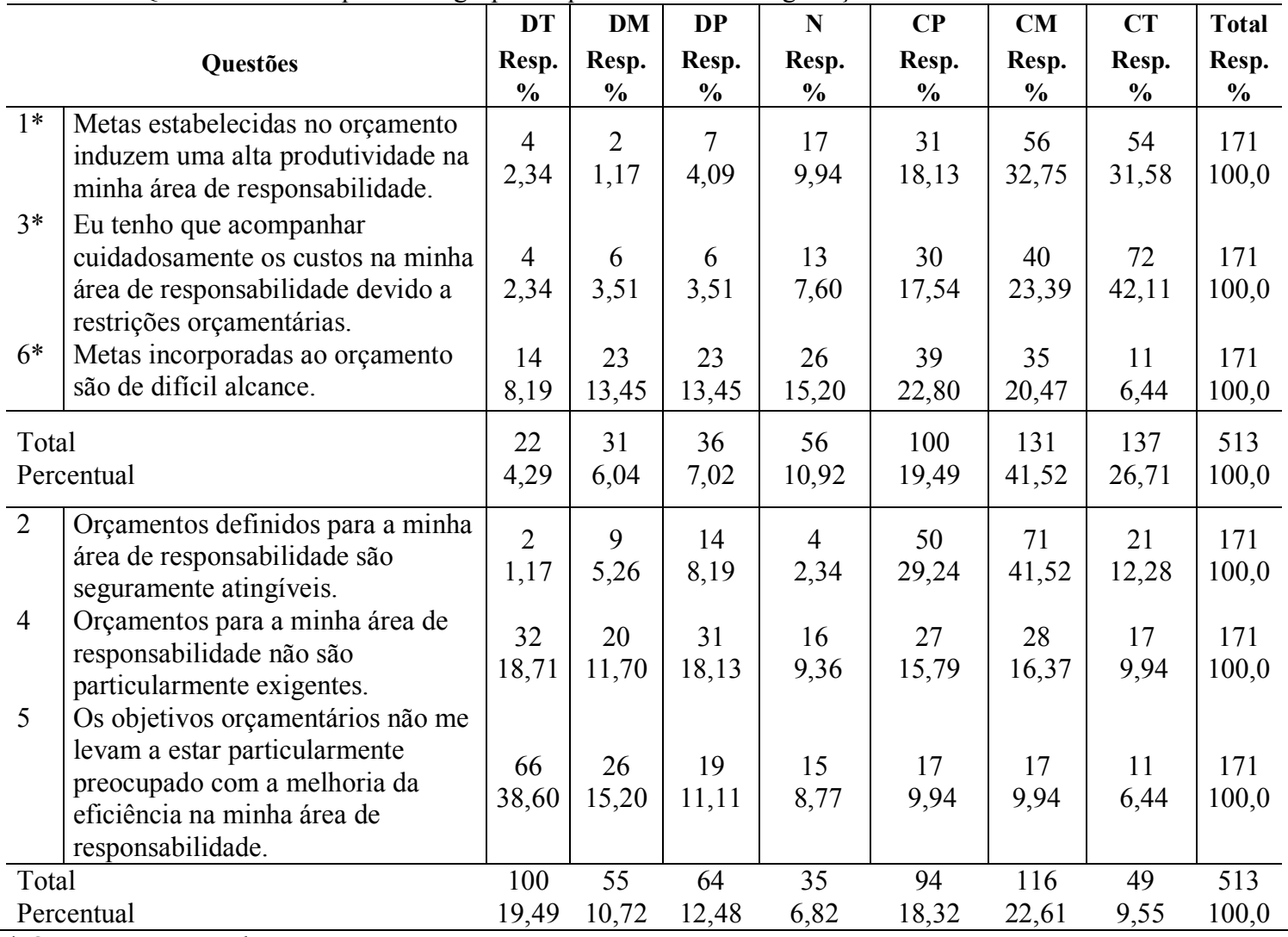

* Questões com escala reversa.

Fonte: dados da pesquisa. 


\subsection{Análise da Assimetria da Informação}

Este tópico apresenta os resultados da pesquisa em relação às questões referentes à assimetria da informação. A Tabela 3 apresenta a quantidade de respostas obtidas em relação a essas questões.

A Tabela 3 mostra que a questão 2 - em comparação com meu superior, eu estou mais familiarizado com as relações operacionais inerentes ao funcionamento interno da minha área de responsabilidade - foi a questão com maior porcentagem
$(87,73 \%)$ de respostas concordantes. A questão 5 - em comparação com meu superior, eu estou mais capacitado para avaliar o potencial impacto de fatores externos sobre as atividades da minha área de responsabilidade - foi a questão que apresentou maior porcentagem de respostas discordantes (22,22\%). Dessa forma, em relação ao grupo de questões sobre a assimetria da informação, percebese elevada porcentagem de respostas nas opções concordo, demonstrando que existe a assimetria da informação na percepção dos respondentes.

Tabela 3 - Quantidade de respostas do grupo de questões sobre a assimetria da informação

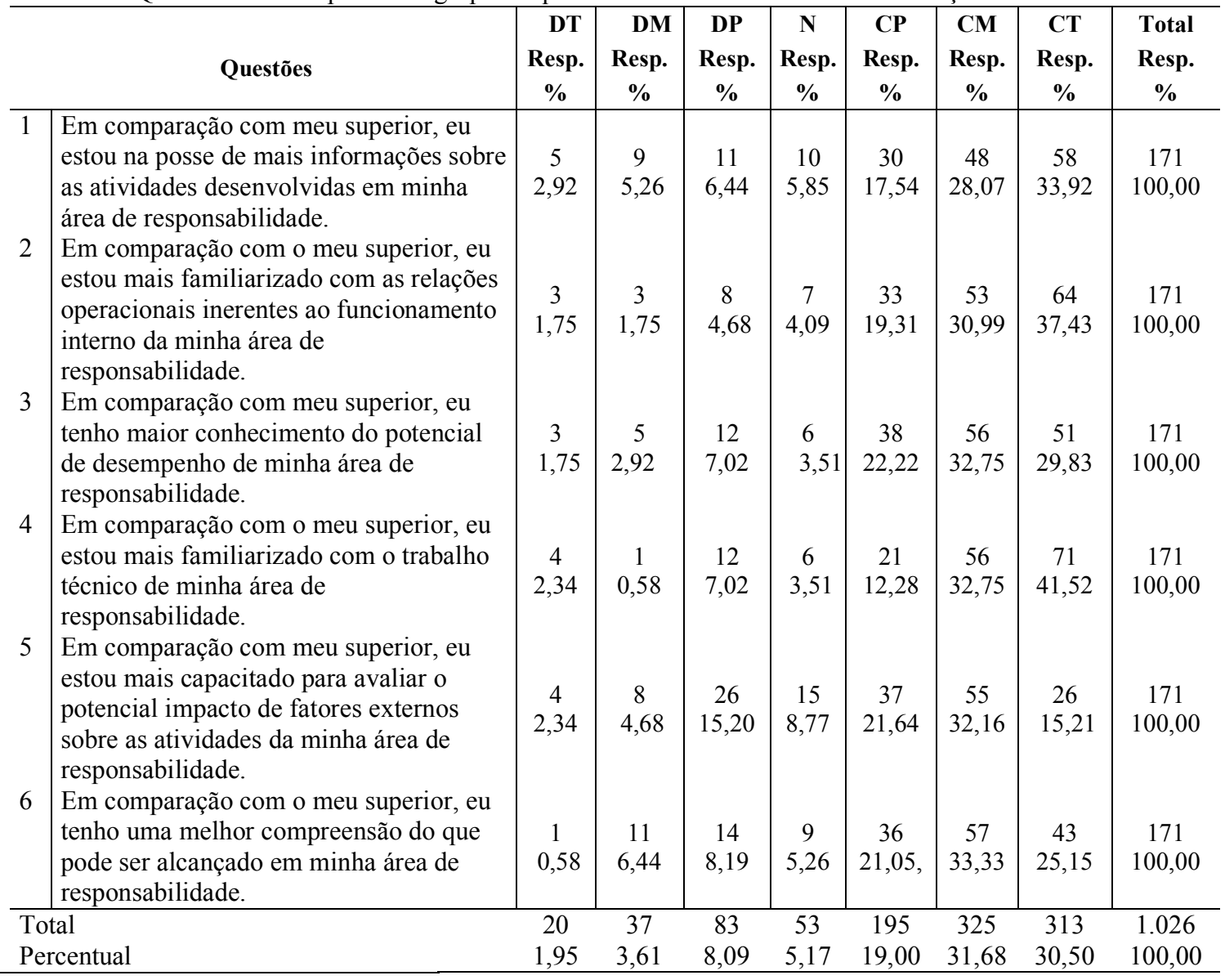

Fonte: dados da pesquisa. 
Foi realizado o teste de MannWhitney da variável gênero em relação às questões da assimetria da informação, porém não apresentou significância em nível de 5\%. No teste de Kruskal-Wallis para as questões referentes a essa assimetria, os resultados obtidos mostram que as variáveis nível de escolaridade e tempo de atuação na função atual não apresentaram significância em nível de $5 \%$.

\subsection{Análise da Participação}

\section{Orçamentária}

Esta seção apresenta os resultados da pesquisa em relação às questões referentes à participação orçamentária. A Tabela 4 apresenta a quantidade de respostas obtidas com referência a essas questões, mostrando nos resultados que houve predomínio nas respostas das opções média e alta. Destaca-se nos resultados da Tabela 4 a elevada porcentagem de respostas na opção média para todas as questões, comparando com as questões sobre a folga orçamentária, a assimetria da informação e o risco na decisão orçamentária.

Tabela 4 - Quantidade de respostas do grupo de questões sobre a participação orçamentária

\begin{tabular}{|c|c|c|c|c|c|c|c|c|c|}
\hline \multicolumn{2}{|r|}{ Questões } & \multirow{2}{*}{$\begin{array}{c}\text { Baixa } \\
\text { Resp. } \\
\% \\
24 \\
14,04\end{array}$} & \multirow{2}{*}{$\begin{array}{c}\vec{\rightarrow} \\
\text { Resp. } \\
\%\end{array}$} & \multirow{2}{*}{$\begin{array}{c}\rightarrow \\
\text { Resp. } \\
\text { \% }\end{array}$} & \multirow{2}{*}{$\begin{array}{c}\text { Média } \\
\text { Resp. } \\
\%\end{array}$} & \multirow{2}{*}{$\begin{array}{c}\vec{\rightarrow} \\
\text { Resp. } \\
\%\end{array}$} & \multirow{2}{*}{$\begin{array}{c}\vec{\rightarrow} \\
\text { Resp. } \\
\text { \% }\end{array}$} & \multirow{2}{*}{$\begin{array}{c}\text { Alta } \\
\text { Resp. } \\
\text { \% } \\
44 \\
25,72\end{array}$} & \multirow{2}{*}{$\begin{array}{c}\begin{array}{c}\text { Total } \\
\text { Resp. } \\
\%\end{array} \\
171 \\
100,00\end{array}$} \\
\hline 1 & $\begin{array}{l}\text { Parcela da elaboração do orçamento em } \\
\text { que eu estou envolvido. }\end{array}$ & & & & & & & & \\
\hline 2 & $\begin{array}{l}\text { Quantidade de informação fornecida a } \\
\text { mim por um superior quando o orçamento } \\
\text { é revisado. }\end{array}$ & $\begin{array}{c}21 \\
12,28\end{array}$ & $\begin{array}{c}8 \\
4,68\end{array}$ & $\begin{array}{c}13 \\
7,60\end{array}$ & $\begin{array}{c}40 \\
23,39\end{array}$ & $\begin{array}{c}26 \\
15,20\end{array}$ & $\begin{array}{c}24 \\
14,04\end{array}$ & $\begin{array}{c}39 \\
22,81\end{array}$ & $\begin{array}{c}171 \\
100,00\end{array}$ \\
\hline 3 & $\begin{array}{l}\text { Frequência de discussões com os } \\
\text { superiores iniciadas por mim e } \\
\text { relacionadas com o orçamento. }\end{array}$ & $\begin{array}{c}22 \\
12,87\end{array}$ & $\begin{array}{c}11 \\
6,43\end{array}$ & $\begin{array}{c}17 \\
9,94\end{array}$ & $\begin{array}{c}41 \\
23,98\end{array}$ & $\begin{array}{c}22 \\
12,87\end{array}$ & $\begin{array}{c}28 \\
16,37\end{array}$ & $\begin{array}{c}30 \\
17,54\end{array}$ & $\begin{array}{c}171 \\
100,00\end{array}$ \\
\hline 4 & $\begin{array}{l}\text { Quantidade de influência que sinto ter no } \\
\text { orçamento final. }\end{array}$ & $\begin{array}{c}22 \\
12,87\end{array}$ & $\begin{array}{c}10 \\
5,85\end{array}$ & $\begin{array}{c}15 \\
8,77\end{array}$ & $\begin{array}{c}40 \\
23,39\end{array}$ & $\begin{array}{c}24 \\
14,04\end{array}$ & $\begin{array}{c}29 \\
16,96\end{array}$ & $\begin{array}{c}31 \\
18,12\end{array}$ & $\begin{array}{c}171 \\
100,00\end{array}$ \\
\hline 5 & $\begin{array}{l}\text { Importância da minha contribuição para o } \\
\text { orçamento. }\end{array}$ & $\begin{array}{c}6 \\
3,51\end{array}$ & $\begin{array}{c}10 \\
5,85\end{array}$ & $\begin{array}{c}10 \\
5,85\end{array}$ & $\begin{array}{c}42 \\
24,56\end{array}$ & $\begin{array}{c}22 \\
12,87\end{array}$ & $\begin{array}{c}25 \\
14,62\end{array}$ & $\begin{array}{c}56 \\
32,74\end{array}$ & $\begin{array}{c}171 \\
100,00\end{array}$ \\
\hline 6 & $\begin{array}{l}\text { Frequência de discussões relacionadas } \\
\text { com o orçamento iniciadas pelo meu } \\
\text { superior quando o orçamento está sendo } \\
\text { elaborado. }\end{array}$ & $\begin{array}{c}24 \\
14,04\end{array}$ & $\begin{array}{c}16 \\
9,36\end{array}$ & $\begin{array}{c}7 \\
4,09\end{array}$ & $\begin{array}{c}47 \\
27,49\end{array}$ & $\begin{array}{c}26 \\
15,20\end{array}$ & $\begin{array}{c}25 \\
14,62\end{array}$ & $\begin{array}{c}26 \\
15,20\end{array}$ & $\begin{array}{c}171 \\
100,00\end{array}$ \\
\hline & entual & $\begin{array}{c}119 \\
11,60\end{array}$ & $\begin{array}{c}66 \\
6,43\end{array}$ & $\begin{array}{c}80 \\
7,80\end{array}$ & $\begin{array}{c}244 \\
23,78\end{array}$ & $\begin{array}{c}140 \\
13,65\end{array}$ & $\begin{array}{c}151 \\
14,72\end{array}$ & $\begin{array}{c}226 \\
22,02\end{array}$ & $\begin{array}{c}1.026 \\
100,00\end{array}$ \\
\hline
\end{tabular}

Fonte: dados da pesquisa.

A questão 6 apresentou a maior porcentagem $(27,49 \%)$ de respostas na opção média. De forma geral, os resultados mostram que os respondentes participam do processo orçamentário de suas empresas, pois a maioria assinalou da opção média à alta $(74,17 \%)$. 
Também foi realizado o teste de Mann-Whitney da variável gênero em relação às questões da participação orçamentária, porém não houve significância em nível de 5\%. Os resultados do teste de Kruskal-Wallis mostraram que as variáveis nível de escolaridade, tempo de atuação na empresa e tempo de atuação na função atual não representaram significância em nível de $5 \%$.

\subsection{Análise do Risco na Decisão}

\section{Orçamentária}

Este item apresenta os resultados da pesquisa em relação às questões referentes ao risco na decisão orçamentária. A Tabela 5 apresenta a quantidade de respostas obtidas em relação a essas questões, cujos resultados evidenciam que $65,50 \%$ dos respondentes escolheram a opção A para a questão referente ao risco na decisão orçamentária. Isso indica que os respondentes são mais conservadores em relação ao risco, sujeitando-se a ele somente quando têm mais de $50 \%$ de chance de ganhar a aposta.

Tabela 5 - Quantidade de respostas da questão sobre o risco na decisão orçamentária

\begin{tabular}{|c|c|c|c|c|}
\hline № & Questões & $\begin{array}{c}\text { A } \\
\text { Resp. } \\
\% \\
\end{array}$ & $\begin{array}{c}\text { B } \\
\text { Resp. } \\
\% \\
\end{array}$ & $\begin{array}{c}\text { Total } \\
\text { Resp. } \\
\% \\
\end{array}$ \\
\hline 1 & $\begin{array}{l}\text { Eu estou disposto a oferecer uma proposta em que você recebe } \$ 5,00 \text { de } \\
\text { certeza ou uma aposta em que você pode receber } \$ 10,00 \text { tendo } X \text { de } \\
\text { chance de isso ocorrer e }(1-X) \text { de chance de receber } \$ 0,00 \text {. Qual o valor } \\
\text { para X (entre } 0 \text { e } 1) \text { para que seja indiferente para você os } \$ 5,00 \text { e decida } \\
\text { fazer a aposta? } \\
\text { a) mais de } 0,50 ; \text { b) menos de } 0,50\end{array}$ & $\begin{array}{c}112 \\
65,50\end{array}$ & $\begin{array}{c}59 \\
34,50\end{array}$ & $\begin{array}{c}171 \\
100,00\end{array}$ \\
\hline
\end{tabular}

Fonte: dados da pesquisa.

Foram realizados os testes de Mann-Whitney e de Kruskal-Wallis, porém nenhuma variável apresentou significância em nível de 5\% em relação à questão sobre o risco na decisão orçamentária.

\subsection{Análise da Relação entre os}

\section{Constructos}

Esta seção contempla a descrição e a análise dos dados realizados por meio do teste de validade de escalas Alpha de Cronbach das variáveis que compõem os constructos e de correlação de Spearman entre os constructos. Inicialmente, a Tabela 6 apresenta a estatística descritiva das variáveis folga orçamentária, assimetria da informação e participação orçamentária. 
Tabela 6 - Estatística descritiva das variáveis

\begin{tabular}{l|r|r|l|r|r|l|r|r|r}
\hline Folga & Média & $\begin{array}{c}\text { Desvio- } \\
\text { padrão }\end{array}$ & Assimetria & Média & \multicolumn{1}{|l|}{$\begin{array}{l}\text { Desvio- } \\
\text { padrão }\end{array}$} & Participação & Média & $\begin{array}{c}\text { Desvio- } \\
\text { padrão }\end{array}$ & N \\
\hline FG1* & 2,3509 & 1,38680 & AS1 & 5,4971 & 1,63194 & PAR1 & 4,4678 & 2,08153 & 171 \\
\hline FG2 & 5,2690 & 1,36258 & AS2 & 5,8012 & 1,35742 & PAR2 & 4,5789 & 1,95491 & 171 \\
\hline FG3* & 2,2690 & 1,51779 & AS3 & 5,5906 & 1,42941 & PAR3 & 4,3684 & 1,93997 & 171 \\
\hline FG4 & 3,8070 & 2,00680 & AS4 & 5,8713 & 1,40831 & PAR4 & 4,4327 & 1,94025 & 171 \\
\hline FG5 & 2,9181 & 2,03044 & AS5 & 5,0000 & 1,56054 & PAR5 & 5,1228 & 1,73954 & 171 \\
\hline FG6* & 3,8187 & 1,73778 & AS6 & 5,4035 & 1,49737 & PAR6 & 4,2515 & 1,93450 & 171 \\
\hline
\end{tabular}

* As questões com escala reversa foram adequadas, ou seja, as respostas 7 se convertem em 1 para formar $o$ constructo da folga.

Fonte: dados da pesquisa.

A análise da validade do constructo da folga orçamentária revelou um Alpha de Cronbach de 0,224, considerando as seis questões do instrumento de pesquisa, nesse caso considerado inaceitável para a continuidade do estudo. Adnan e Sulaiman (2007), por exemplo, encontraram um valor de 0,57 .

Dessa maneira, procedeu-se à verificação para a eliminação de questões avaliando-se a correlação item-total corrigido (Corrected Item-Total Correlation) de cada questão do constructo. As questões 2 e 6 apresentaram um valor negativo $(-0,290$ e $-0,147$, respectivamente) e foram eliminadas; logo, o Alpha de Cronbach atingiu o valor de
0,572, considerado fraco (GLIEM; GLIEM, 2003), porém de acordo com estudos anteriores.

Em continuidade, os constructos de participação orçamentária e de assimetria da informação apresentaram valores para o Alpha de Cronbach de 0,909 e 0,890 (confiabilidade excelente), sem a indicação de eliminação de questões.

Cada um dos constructos da pesquisa foi formado pela soma das questões que o compõem, à exceção do constructo da folga orçamentária, composta pela soma das questões 1, 3, 4 e 5 , e para o constructo risco, composto somente de uma questão. A Tabela 7 apresenta a estatística descritiva dos constructos da pesquisa.

Tabela 7 - Estatística descritiva dos constructos

\begin{tabular}{l|r|r|r|r|r|c}
\hline \multicolumn{1}{c|}{ Variáveis } & \multicolumn{1}{c|}{ N } & \multicolumn{1}{c|}{ Mínimo } & \multicolumn{1}{c}{ Máximo } & \multicolumn{1}{c}{ Média } & Desvio-Padrão & Alpha de Cronbach \\
\hline Folga & 171 & 4,00 & 22,00 & 11,3450 & 4,65431 & 0,572 \\
\hline Assimetria & 171 & 8,00 & 42,00 & 33,1637 & 7,15024 & 0,890 \\
\hline Participação & 171 & 6,00 & 42,00 & 27,2222 & 9,61542 & 0,909 \\
\hline Risco & 171 & 1,00 & 2,00 & 1,3450 & 0,47677 & $*$ \\
\hline
\end{tabular}

Fonte: dados da pesquisa. 
Após a avaliação da confiabilidade dos constructos, analisou-se a correlação entre eles por meio do teste de correlação de Spearman, cujos resultados são apresentados na Tabela 8 .

Tabela 8 - Coeficientes de correlação de Spearman entre os constructos

\begin{tabular}{l|c|c|c|c}
\hline \multicolumn{1}{c|}{ Variáveis } & (1) & (2) & (3) & (4) \\
\hline Folga orçamentária (1) & 1,000 & $-0,069$ & $-0,073$ & $-0,014$ \\
\hline Assimetria da informação (2) & $-0,069$ & 1,000 & $0,272 * *$ & $-0,084$ \\
\hline Participação orçamentária (3) & $-0,073$ & $0,272 * *$ & 1,000 & $-0,134$ \\
\hline Risco na decisão orçamentária (4) & $-0,014$ & $-0,084$ & $-0,134$ & 1,000
\end{tabular}

Nota: ** Correlação significante em nível de 0,01

Fonte: dados da pesquisa.

Percebe-se na Tabela 8 que somente o constructo da assimetria da informação apresenta coeficiente de correlação positiva de 0,272 , em nível de significância de $1 \%$, com o constructo da participação orçamentária. As demais correlações analisadas não foram significativas. Quanto à análise das hipóteses, seguiram-se os critérios do Quadro 3, elaborado a partir da análise da literatura.

Quadro 3 - Correlações esperadas entre os constructos da pesquisa

\begin{tabular}{|l|c|}
\hline \multicolumn{1}{|c|}{ Hipótese } & $\begin{array}{c}\text { Correlação Esperada com a } \\
\text { variável Folga orçamentária }\end{array}$ \\
\hline $\begin{array}{l}\text { H1 - quanto maior a participação orçamentária da média gerência na } \\
\text { elaboração do orçamento menor será a folga orçamentária }\end{array}$ & Negativa \\
\hline $\begin{array}{l}\text { H2 - quanto maior a assimetria da informação entre as gerências média e } \\
\text { superior na elaboração do orçamento maior será a folga orçamentária. }\end{array}$ & Positiva \\
\hline $\begin{array}{l}\text { H3 - quanto maior for a neutralidade da gerência média em relação ao risco na } \\
\text { elaboração do orçamento menor será a folga orçamentária }\end{array}$ & Positiva \\
\hline
\end{tabular}

Fonte: elaboração própria.

Realizados os testes de correlação de Spearman, apresentados na Tabela 8 para os constructos de pesquisa, observouse que as hipóteses de estudo não foram confirmadas na percepção dos respondentes, apesar de o teste de validade das escalas ter apresentado valores satisfatórios para o Alpha de Cronbach (Tabela 7).
Os dados empíricos coletados mostraram que a gerência média não considera que utiliza orçamentos com folga e não toma riscos financeiros para decidir, mas apresenta assimetria de informação entre as gerências superior e média, e participa no processo orçamentário. Os resultados obtidos não sugerem uma relação entre a folga 
orçamentária e os constructos de participação, assimetria e risco.

Nesse sentido, Maiga e Jacobs (2007) sugerem que a falta de uma relação direta entre a folga orçamentária e a participação pode estar relacionada com outros aspectos da organização, como a justiça organizacional e o comprometimento com as metas.

Entretanto, observou-se uma correlação positiva e significante entre os constructos de assimetria da informação e de participação orçamentária. Retomando Dunk (1993), a média gerência pode buscar benefícios para a sua unidade em detrimento de toda a organização, ao reter informações perante a gerência superior. Conforme Young (1985) propõe, os gerentes, mesmo em um ambiente de participação orçamentária, podem reter informação sobre a definição das metas e o seu desempenho esperado.

Apesar de estudos, como o de Baiman (1990), afirmarem que a participação orçamentária pode diminuir a assimetria por meio do compartilhamento da informação e da melhoria da comunicação entre os níveis gerenciais, os dados da pesquisa informaram o contrário, indicando que um ambiente de alta participação da média gerência pode conviver com a falta de compartilhamento de informações sobre as atividades desenvolvidas entre os níveis gerenciais das organizações em que atuam os respondentes, semelhantemente ao estudo de Shields e Young (1993) e Lavarda e Almeida (2013).

\section{CONCLUSÃO}

O objetivo geral desta investigação foi verificar a relação da assimetria da informação, da participação orçamentária e da posição de risco na criação da folga orçamentária pela média gerência de organizações. Para atingir esse objetivo, a pesquisa caracterizou-se pela utilização de metodologia descritiva, abordagem quantitativa e procedimento de levantamento ou survey.

A amostra da pesquisa é composta por 171 respondentes matriculados nos cursos de pós-graduação lato sensu na área de Ciências Contábeis e Administração de instituições de ensino do estado de Santa Catarina, no período de dezembro de 2010 a maio de 2011, que se enquadraram nos cargos de média gerência. Foram considerados na amostra os questionários nos quais o cargo/função desempenhado atualmente se encaixasse nas seguintes opções: supervisor, gerente administrativo, gerente financeiro, gerente de produção, gerente de recursos humanos, gerente comercial e outros, desde que fossem gerentes de departamento.

Para responder a questão de 
pesquisa, utilizou-se o teste de hipóteses. As hipóteses 1, 2 e 3 foram analisadas por meio da correlação de Spearman para dados não paramétricos, mas não foram confirmadas pelos dados empíricos, não sendo possível inferir pelos resultados se a participação orçamentária, a assimetria da informação e o risco no orçamento estão relacionados com a folga orçamentária. Entretanto, identificaram-se evidências sobre a relação entre a participação orçamentária e a assimetria da informação, cujo tema ainda encontra resultados contraditórios na literatura.

O estudo contribui teoricamente para o tema da folga orçamentária, relacionada com a assimetria da informação, a participação orçamentária e o risco no orçamento, ainda não explorado em pesquisas no Brasil. O tema vem sendo estudado mais frequentemente na literatura internacional, em que se podem destacar os estudos de Ho e Vera-Muñoz (2001), Ho, Keller e Keltyka (2002), Parker e Kyj (2006), Adnan e Sulaiman (2007), Sprinkle, Williamson e Upton (2008), Kyj e Parker (2008), fazendo surgir o interesse em abordar o assunto com gerentes de organizações nacionais.

O estudo se torna relevante, pois apresenta a percepção da média gerência integrante da amostra em relação à folga orçamentária. $\mathrm{O}$ estudo pretendeu servir como base para alertar as organizações sobre a forma de conduzir suas ações, intensificando aquelas que possam contribuir para o processo orçamentário.

Para pesquisas futuras, recomendase a ampliação da amostra do estudo, incluindo também a percepção da alta gestão sobre as variáveis pesquisadas. Também se recomenda a inclusão de outras variáveis em pesquisas, tais como motivação, reputação, ênfase orçamentária, identificando os efeitos diretos e indiretos na criação de folga orçamentária.

\section{PUBLICAÇÃO}

Uma versão prévia do artigo foi apresentada no Congresso Brasileiro de Custos 2011.

\section{REFERÊNCIAS}

ADNAN, S. M.; SULAIMAN, M. Organizational, cultural and religious factors of budgetary slack creation: Empirical evidence from Malaysia. International Review of Business Research Papers, v. 3, n. 3, p. 17-34, Aug. 2007.

ANTHONY, R. N.; GOVINDARAJAN, V. Sistemas de controle gerencial. São Paulo: Atlas, 2001.

BAIMAN, S. Agency research in managerial accounting: A second look. Accounting, Organizations and Society, v. 15, p. 341-371, 1990.

BOURGEOIS, L. On the measurement of organizational slack. Academy of

Management Review, v. 6, p. 29-39, 1981. 
CERVO, A. L.; BERVIAN, P. A.

Metodologia científica. 5. ed. São Paulo: Prentice Hall, 2002.

CHOW, C. W.; COOPER, J. C.; WALLER, W. S. Participative budgeting: effects of a truth-inducing pay scheme and information asymmetry on slack and performance. The Accounting Review, v. 63, n. 1, p. 111-122, 1988.

DUNK, A. S. The Effect of Budget Emphasis and Information Asymmetry on the Relation between Budgetary Participation and Slack. American Accounting Association, v. 68, n. 2, p. 400-410, Apr.1993.

GARRISON, R. H.; NOREEN, E. W. Contabilidade gerencial. Rio de Janeiro: LTC Editora, 2001.

GIL, A. C. Métodos e técnicas de pesquisa social. 5. ed. São Paulo: Atlas, 1999.

GLIEM, J. A.; GLIEM, R. R. Calculating, interpreting and reporting Cronbach's alpha reliability coefficient for Likert-type scales. In: 2003 Midwest Research to Practice Conference in Adult, Continuing, and Community Education.

Proceedings... 2003. Disponível em: $<$ https://scholarworks.iupui.edu/bitstream/ handle/1805/344/Gliem\%20\&\%20..?seque nce $=1>$. Acesso em: jan. 2013 .

HANSEN, D. R.; MOWEN, M. M. Gestão de custos. São Paulo: Pioneira, 2001.

HENDRIKSEN, E. S.; VAN BREDA, M. F. Teoria da Contabilidade. São Paulo: Atlas, 1999.

HO, J. L; VERA-MUÑOZ, S. C. Opportunism in Capital Budget Recommendations: The Effects of Past Performance and Its Attributions. Decision Sciences, v. 32, n. 3, 2001.
HO, J. L Y.; KELLER, L. R.; KELTYKA, P. Effects of Outcome and Probabilistic Ambiguity on Managerial Choices. The Journal of Risk and Uncertainty, 24:1; 47-74, 2002.

JOHNSTON, W.; KIM, K. Performance, attribution, and expectancy linkages in personal selling. Journal of Marketing, v. 58, p. 68-81, 1994.

KYJ, L.; PARKER, R. J. Antecedents of Budget Participation: Leadership Style, Information Asymmetry, and Evaluative Use of Budget. A Journal of Accounting, Finance and Business Studies, v. 44, n. 4, p. 423-444, 2008.

KIM, D. C. Risk Preferences in Participative Budgeting. American Accounting Association, v. 67, n. 2, p. 303-318, Apr. 1992.

LAVARDA, C. E. F., ALMEIDA, D. M. Budget participation and informational asymmetry: a study in a multinational company. Brazilian Business Review, v. 10, n. 2, p. 72-94, 2013.

LUKKA, K. Budgetary biasing in organizations: theoretical framework and empirical evidence. Accounting, Organizations and Society, v. 13, p. 281301, 1988.

MAIGA, A. S.; JACOBS, F. A. Budget participation's influence on budget slack: the role of fairness perceptions, trust and goal commitment. Journal of Applied Management Accounting Research, v. 5, n. 1, p. 39-58, 2007.

MARTINS, G. A. THEÓPHILO, C. R. Metodologia da Investigação Científica para Ciências Sociais Aplicadas. São Paulo: Atlas, 2009.

MERCHANT, K. A. Budgeting and the propensity to create budgetary slack. 
Accounting, Organizations and Society, v. 10, p. 201-210, 1985.

MILANI, K. The relationship of participation in budget-setting to industrial supervisor perfor- mance and attitudes: A field study. The Accounting Review, v. 50, p. 274-285, Apr. 1975.

PARKER, R. J.; KYJ, L. Vertical information sharing in the budgeting process. Accounting, Organizations and Society, v. 31, p. 27-45, 2006.

RICHARDSON, R. J. Pesquisa social: métodos e técnicas. 2. ed. São Paulo: Atlas, 1989.

SHIELDS, M. D.; YOUNG, S. M. Antecedents and Consequences of Participative Budgeting: Evidence on the Effects of Asymmetrical Information. Journal of Management Accounting Research, v. 5, p. 265-280, 1993.

SHIELDS, J. F.; SHIELDS, M. D. Antecedents of participative budgeting. Accounting, Organization and Society, v. 23 , n. 1, p. 49-76, 1998.

SPRINKLE. G. B.; WILLIAMSON, M.G.; UPTON, D. R. The effort and risk-taking effects of budget-based contracts.

Accounting, Organizations and Society, v. 33, p. 436-452, 2008.

SULLIVAN, K.; KIDA, T. The effect of multiple reference points and prior gains and losses on managers' risky decision making. Organizational Behavior and Human Decision Processes, v. 64, p. 7683, 1995.

VAN DER STEDE, W. A. The relationship between two consequences of budgetary controls: budgetary slack creation and managerial short-term orientation. Accounting, Organizations and Society, p. 609-622, 2000.
WEBB, R. A. The Impact of Reputation and Variance Investigations on the Creation of Budget Slack. Accounting, Organizations and Society, v. 27, p. 361 378, 2002.

YOUNG, S. M. Participative budgeting: The effects of risk aversion and asymmetric information on budgetary slack. Journal of Accounting Research, v. 23, n. 2 , p. 829-842, 1985. 